\title{
Capacity of Advance Right-Turn Motorized Vehicles at Signalized Intersections for Mixed Traffic Conditions
}

\author{
Bing Li ${ }^{1}$, Wei Cheng $\mathbb{D}^{1}$, Yiming Bie ${ }^{2}$, and Bin Sun ${ }^{3}$ \\ ${ }^{1}$ Faculty of Transportation Engineering, Kunming University of Science and Technology, Kunming, Yunnan 650093, China \\ ${ }^{2}$ School of Transportation Science and Engineering, Harbin Institute of Technology, Harbin 150091, China \\ ${ }^{3}$ Department of Creative Technologies, Blekinge Institute of Technology, Karlskrona 37179, Sweden
}

Correspondence should be addressed to Wei Cheng; chengwei_ding@kmust.edu.cn

Received 15 October 2018; Revised 23 March 2019; Accepted 8 April 2019; Published 22 April 2019

Academic Editor: Alexander Paz

Copyright (C) 2019 Bing Li et al. This is an open access article distributed under the Creative Commons Attribution License, which permits unrestricted use, distribution, and reproduction in any medium, provided the original work is properly cited.

\begin{abstract}
Right-turn motorized vehicles turn right using channelized islands, which are used to improve the capacity of intersections. For ease of description, these kinds of right-turn motorized vehicles are called advance right-turn motorized vehicles (ARTMVs) in this paper. The authors analyzed four aspects of traffic conflict involving ARTMVs with other forms of traffic flow. A capacity model of ARTMVs is presented here using shockwave theory and gap acceptance theory. The proposed capacity model was validated by comparison to the results of the observations based on data collected at a single intersection with channelized islands in Kunming, the Highway Capacity Manual (HCM) model and the VISSIM simulation model. To facilitate engineering applications, the relationship describing the capacity of the ARTMVs with reference to the distance between the conflict zone and the stop line and the relationship describing the capacity of the ARTMVs with reference to the effective red time of the nonmotorized vehicles moving in the same direction were analyzed. The authors compared these results to the capacity of no advance right-turn motorized vehicles (NARTMVs). The results show that the capacity of the ARTMVs is more sensitive to the changes in the arrival rate of nonmotorized vehicles when the arrival rate of the nonmotorized vehicles is $500(\mathrm{veh} / \mathrm{h}) \sim 2000(\mathrm{veh} / \mathrm{h})$ than when the arrival rate is some other value. In addition, the capacity of NARTMVs is greater than the capacity of ARTMVs when the nonmotorized vehicles have a higher arrival rate.
\end{abstract}

\section{Introduction}

The method of allowing right-turn motorized vehicles in the front to turn right using channelized islands is used to improve the capacity of intersections. Where channelized right-turn occurs, the ARTMVs (advance right-turn motorized vehicles) can be considered to have no effect on the capacity or delay of the intersection when they pass through the intersection [1]. However, this view is not suitable for high traffic volumes and complex traffic environments, particularly in some countries with mixed traffic conditions, such as China. The authors found that the traffic at most of China's intersections is not consistent with ARTMVs. The four aspects of traffic flow are shown in Figure 1. The first aspect is that, before entering the nonmotorized vehicle lane, the ARTMVs come into conflict with motorized vehicles passing straight through the intersection in the same direction [1-3]. The second aspect is that, when ARTMV is entering the nonmotorized vehicle lane, the traffic conflicts with the nonmotorized vehicles moving in the same direction $[4,5]$. The third aspect is that the traffic conflicts with pedestrians as the nonmotorized vehicles move in the same direction [6-8]. The fourth aspect is that, after crossing the pedestrians, the traffic conflicts with the through traffic nonmotorized vehicles on the left of the ARTMVs [9]. For ease of understanding, Figure 1 depicts the through nonmotorized vehicles flow on the north approach.

As shown in Table 1, for most ARTMV flows, the conflicts involving nonmotorized vehicles moving in the same direction are the most severe conflicts (the average conflict time per ARTMV is significantly higher than the other aspects). Thus, this paper mainly studies the capacity of ARTMVs under the influence of nonmotorized vehicles moving in the same direction. Some scholars have analyzed and studied the 


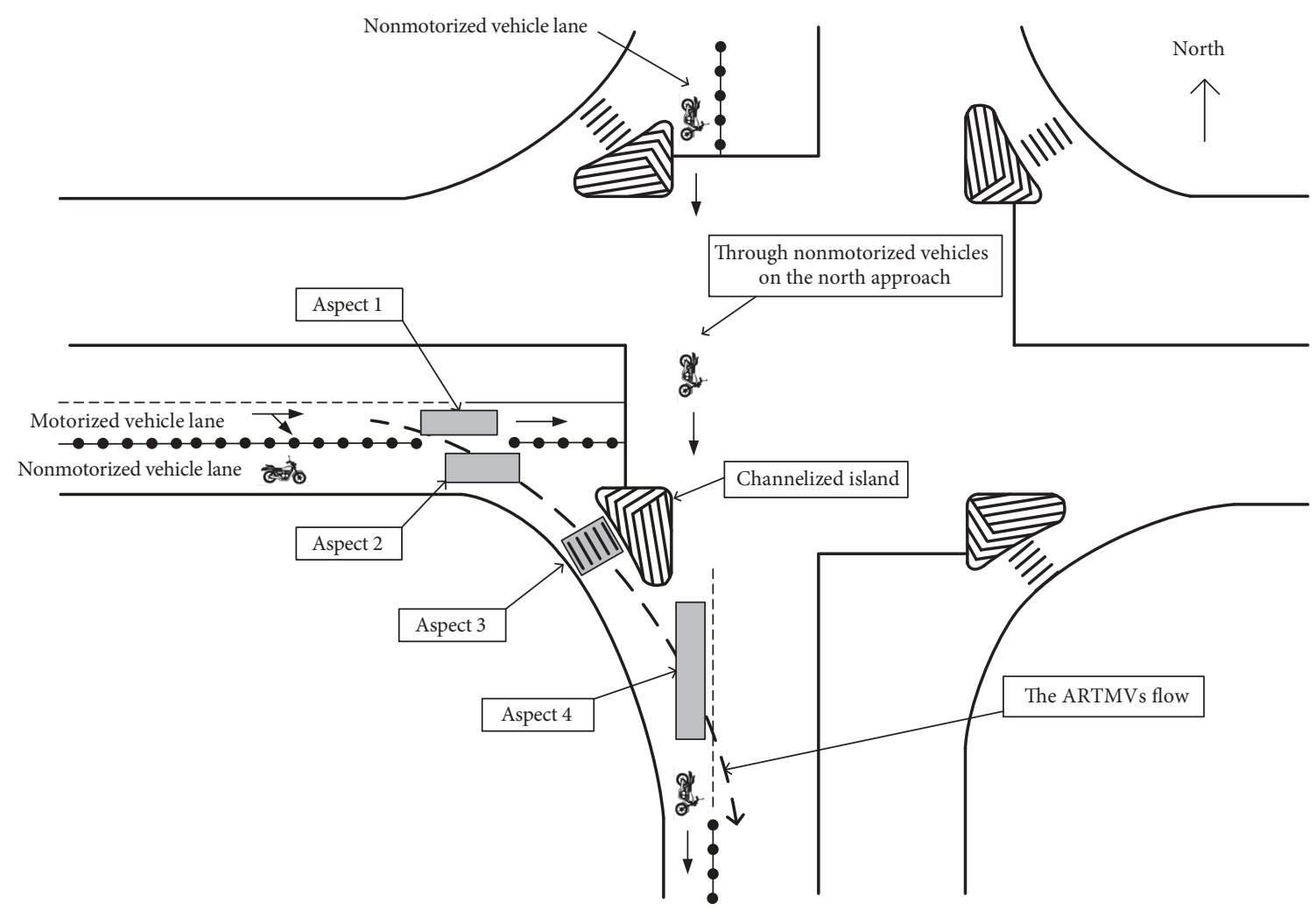

FIgURE 1: Four aspects of traffic conflicts of the ARTMVs.

TABLE 1: Average conflict times per ARTMV under each aspect.

\begin{tabular}{|c|c|c|c|c|c|c|}
\hline \multicolumn{2}{|c|}{ Site } & \multicolumn{5}{|c|}{$\begin{array}{l}\text { Average conflict times per ARTMV under } \\
\text { each aspect }\end{array}$} \\
\hline Intersection & Approach & $\begin{array}{l}\text { Sample } \\
\text { size }\end{array}$ & Aspect 1 & Aspect 2 & Aspect 3 & Aspect 4 \\
\hline \multirow{2}{*}{$\begin{array}{l}\text { Huancheng } \\
\text { Bei-Beijing }\end{array}$} & East & 150 & 0.21 & 0.58 & 0.35 & 0.12 \\
\hline & West & 150 & 0.23 & 0.78 & 0.33 & 0.21 \\
\hline \multirow{6}{*}{$\begin{array}{l}\text { Huanchengdong- } \\
\text { Chuan } \\
\text { Jin } \\
\text { Huanchengdong- } \\
\text { Dong Feng } \\
\text { Dong } \\
\text { Huan Cheng } \\
\text { Nan-Xichang }\end{array}$} & North & 150 & 0.34 & 0.84 & 0.20 & 0.37 \\
\hline & South & 150 & 0.24 & 0.79 & 0.45 & 0.34 \\
\hline & East & 150 & 0.19 & 0.65 & 0.42 & 0.27 \\
\hline & West & 150 & 0.34 & 0.67 & 0.32 & 0.34 \\
\hline & East & 150 & 0.11 & 0.70 & 0.36 & 0.23 \\
\hline & South & 150 & 0.29 & 0.63 & 0.30 & 0.37 \\
\hline \multicolumn{2}{|c|}{ Average } & & 0.25 & 0.71 & 0.34 & 0.28 \\
\hline
\end{tabular}

traffic characteristics of ARTMVs under these conditions. Zhou et al. [5] analyzed the effects of bicycle traffic on vehicular delays at signalized intersections with pre-rightturn lanes. In the Highway Capacity Manual (HCM 2010) [4], the capacity of ARTMVs was calculated using a modified saturation flow rate while considering the influence of the occupancy of nonmotorized vehicles. However, this method was used to estimate the capacity without considering the impact of the distribution of the arrival of nonmotorized vehicles, which can lead to an overestimation of capacity. The previously cited references include analyses of the traffic conflicts that occur between ARTMVs and nonmotorized vehicles that are moving in the same direction. However, none of these studies considered the influence of the capacity of ARTMVs when the nonmotorized vehicle queue overflowed into the conflict zone.

In this paper, the shockwave theory and the gap acceptance theory are used to describe the conflicts between ARTMVs and nonmotorized vehicles moving in the same direction and a capacity model of ARTMVs is proposed. The sensitivity of the reliability (as will be described in detail in the Sensitivity Analysis section) of the proposed model was analyzed to ensure the stability and reliability of its use in engineering applications. In addition, from the data collected 


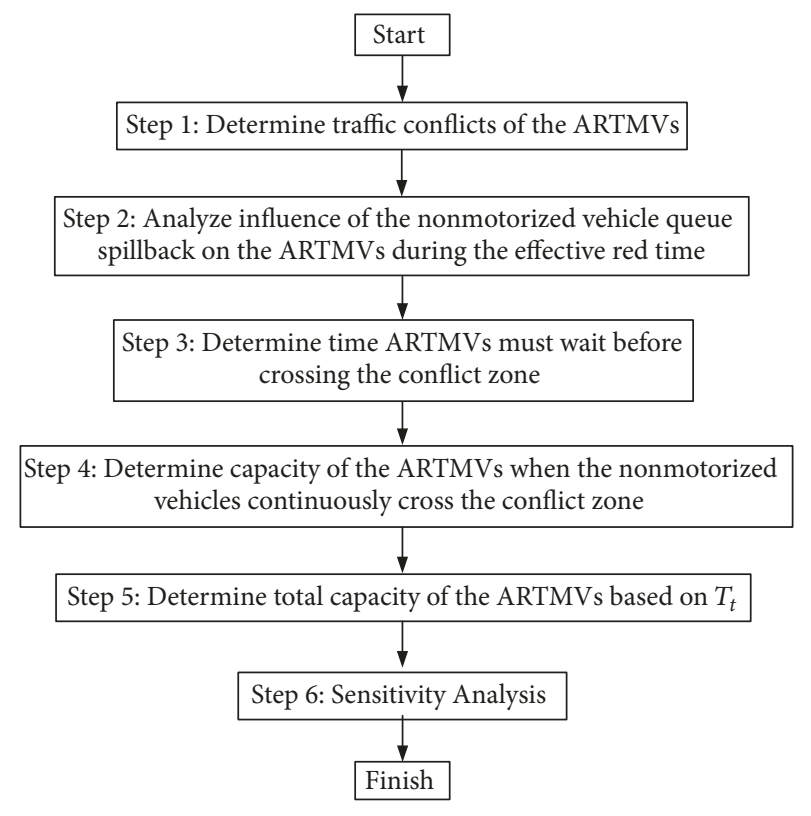

FIGURE 2: The roadmap of the paper.

at typical intersections in Kunming, several model results and other factors were compared to demonstrate the rationality and validity of the proposed model. The roadmap of the paper is shown in Figure 2.

For the reader's convenience, a list of the parameters used in the model is summarized in Table 2.

\section{Traffic Conflicts of the ARTMVs}

The four aspects of the traffic conflicts of the ARTMVs are listed in the Introduction. The following paragraphs discuss each of these traffic conflicts.

\subsection{Traffic Conflicts with Straight-Through Motor Vehicles} Moving in the Same Direction. The conflicts that occur between the ARTMVs and the motorized vehicles passing straight through an intersection are mainly visible in the shared through and right lanes. They can be categorized into the following two situations:

(1) Situation I: ARTMVs are not blocked by straightthrough motor vehicles. In this situation, the capacity of the ARTMVs can be considered the saturation flow rate.

(2) Situation II: ARTMVs are blocked by motorized vehicles passing straight through the intersection. This situation usually occurs when the straight-through motor vehicles overflow into the conflict zone during an effective red time.

\subsection{Traffic Conflicts with Nonmotorized Vehicles Moving in the} Same Direction. The conflicts that occur between ARTMVs and nonmotorized vehicles moving in the same direction can also be categorized into the following two situations:

(1) Situation I: The queue of nonmotorized vehicles overflows into the conflict zone. During the effective red time, as the nonmotorized vehicles arrive at the intersection, they

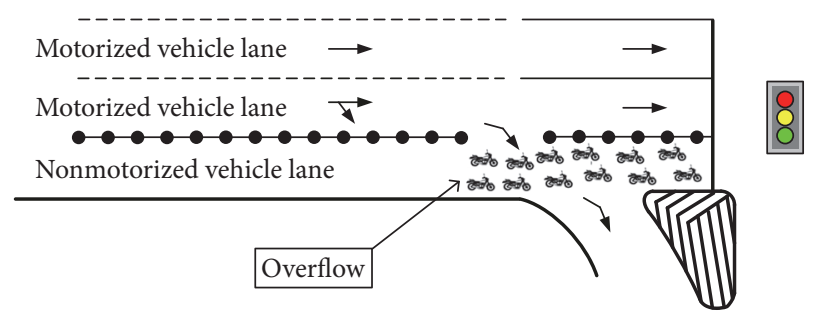

FIGURE 3: Nonmotorized vehicle queue overflows into the conflict zone.

will accumulate at relatively low speeds. At the beginning of the effective red time, the ARTMVs can take advantage of the gaps in the flow of nonmotorized vehicles to pass through the conflict zone. As the volume of nonmotorized vehicles increases during the peak hours, however, their queue overflows into the conflict zone, as shown in Figure 3, especially at the shorter distance between the conflict zone and the stop line. When the nonmotorized vehicle queue overflows into the conflict zone, these gaps disappear. The ARTMVs wait in the conflict zone until the nonmotorized vehicle queue dissipates and the gaps reappear. This allows the ARTMVs to cross the conflict zone.

(2) Situation II: Nonmotorized vehicles do not stop when they pass through the conflict zone. When the nonmotorized vehicle queue does not overflow into the conflict zone, the ARTMVs can take advantage of the gaps in the flow of nonmotorized vehicles to pass through the conflict zone. At this point, only the effect of the random arrival of nonmotorized vehicles on the ARTMVs is considered.

2.3. Traffic Conflicts with Pedestrians. In most cases, both the ARTMVs and the pedestrians crossing the right-turn lane are unsignalized. ARTMVs usually cross the conflict zone only after following strict rules to ensure the safety of pedestrians. When the volume of ARTMVs and the volume of pedestrians are both low, the probability of a collision occurring between the two is also small. As the volume of both groups increases, the risk to pedestrians increases, and it also becomes more difficult for ARTMVs to pass through the intersection. Severe cases can cause interference to both nonmotorized vehicles and straight-through motorized vehicles moving in the same direction.

2.4. Traffic Conflicts with Nonmotorized Vehicles on the Left. When the nonmotorized vehicles on the left are waiting during the effective red time, they do not affect the ARTMVs, and they can cross the conflict zone during saturated flow. When the nonmotorized vehicles on the left cross the intersection while the light is green, the nonmotorized vehicles affect the movement of the ARTMVs, especially when many nonmotorized vehicles are waiting for a green time. At this time, the nonmotorized vehicles pass through the conflict zone at a high density, and only after this do the ARTMVs take advantage of the gap before the subsequent arrivals of nonmotorized vehicles in order to cross the conflict zone. If the ARTMVs wait too long, a queue forms, 
TABLE 2: Definition of Parameters.

\begin{tabular}{|c|c|}
\hline Parameters & Definition \\
\hline$t_{L}(\mathrm{~s})$ & $\begin{array}{l}\text { The time from the start of the effective red time to the initial moment when the ARTMVs must } \\
\text { wait to cross the conflict zone }\end{array}$ \\
\hline$L(\mathrm{~m})$ & $\begin{array}{c}\text { The distance between the stop line and the position of the vehicle at which the moment }\left(t_{L}\right) \text { takes } \\
\text { place }\end{array}$ \\
\hline$W(\mathrm{~m})$ & The width of the nonmotorized vehicle lane \\
\hline$\lambda(\mathrm{veh} / \mathrm{h})$ & The rate of arrival of the nonmotorized vehicles \\
\hline$Q\left(\mathrm{~m}^{2} / \mathrm{veh}\right)$ & $\begin{array}{c}\text { The average road area occupied per nonmotorized vehicle when nonmotorized vehicles are } \\
\text { waiting in the queue during the effective red time }\end{array}$ \\
\hline$t_{R}(\mathrm{~s})$ & The effective red time of nonmotorized vehicles \\
\hline$t_{G}(\mathrm{~s})$ & The effective green time of nonmotorized vehicles \\
\hline$T_{c}(\mathrm{~s})$ & The signal cycle \\
\hline$v_{w s}(\mathrm{~m} / \mathrm{s})$ & The starting wave speed of nonmotorized vehicles \\
\hline$v_{w p}(\mathrm{~m} / \mathrm{s})$ & The stopping wave speed of nonmotorized vehicles \\
\hline$v(\mathrm{~m} / \mathrm{s})$ & The speed of the nonmotorized vehicles \\
\hline$u(\mathrm{veh} / \mathrm{h})$ & The volume of the nonmotorized vehicles \\
\hline$k\left(\mathrm{veh} / \mathrm{m}^{2}\right)$ & The density of the nonmotorized vehicles \\
\hline$T_{l}(\mathrm{~s})$ & $\begin{array}{l}\text { The time ARTMVs must wait before crossing the conflict zone because of spillback from the } \\
\text { nonmotorized vehicle queue }\end{array}$ \\
\hline$t_{L}^{\prime}(\mathrm{s})$ & $\begin{array}{c}\text { The time during which the shockwave propagates backward from the stop line to the } \\
\text { perpendicular line S }\end{array}$ \\
\hline$t_{w s}(\mathrm{~s})$ & $\begin{array}{c}\text { The time required for the queue of nonmotorized vehicles before the perpendicular line } \mathrm{S} \text { to } \\
\text { dissipate }\end{array}$ \\
\hline$L_{t_{R}}(\mathrm{~m})$ & The queue of nonmotorized vehicles by the end of the effective red time \\
\hline$t_{w s}^{\prime}(\mathrm{s})$ & $\begin{array}{l}\text { The time required for the nonmotorized vehicle queue before the perpendicular line } S \text { to } \\
\text { completely dissipate }\end{array}$ \\
\hline$t_{n}(\mathrm{~s})$ & The headway of the nonmotorized vehicles \\
\hline$t_{r s}(\mathrm{~s})$ & The saturation headway of the ARTMVs \\
\hline$t_{n s}(\mathrm{~s})$ & The minimum headway of the nonmotorized vehicles \\
\hline$t_{c}(\mathrm{~S})$ & The critical gap in the flow of the nonmotorized vehicles \\
\hline$p(t)$ & The probability density of $t_{n}$ \\
\hline$T_{t}(\mathrm{~s})$ & $\begin{array}{l}\text { The time it takes for a nonmotorized vehicle to pass through the conflict zone during a signal } \\
\text { cycle, assuming that the vehicle does not stop }\end{array}$ \\
\hline$C_{T_{c}}(\mathrm{veh} / \mathrm{h})$ & The number of ARTMVs that can pass through the conflict zone in a signal cycle $T_{c}$ \\
\hline$C_{R}(\mathrm{veh} / \mathrm{h})$ & The capacity of the ARTMVs \\
\hline$C_{\text {obs }}(\mathrm{veh} / \mathrm{h})$ & The observed capacity of the ARTMVs \\
\hline$C_{\text {cal }}(\mathrm{veh} / \mathrm{h})$ & The calculated capacity of the ARTMVs \\
\hline
\end{tabular}

affecting pedestrians, nonmotorized vehicles, and straightthrough motorized vehicles moving in the same direction.

In summary, when the ARTMVs pass through an intersection, they cross the four conflict zones. Therefore, the capacity of the ARTMVs should be the minimum value of the four aspects of the traffic conflicts listed earlier. As described in the Introduction, for most of the ARTMV flows, the most severe traffic conflicts occur with nonmotorized vehicles moving in the same direction. To be specific, this aspect of traffic conflict has the greatest influence on the capacity of the ARTMVs. Therefore, this paper mainly studies the capacity of ARTMVs under the influence of nonmotorized vehicles moving in the same direction.

\section{Capacity Model of the ARTMVs}

3.1. Influence of the Nonmotorized Vehicle Queue Spillback on the ARTMVs during the Effective Red Time. The previous analysis of the conflicts between the ARTMVs and the nonmotorized vehicles moving in the same direction shows that spillback from the nonmotorized vehicle queue had a pronounced impact on the capacity of the ARTMVs crossing the intersection. Hence, one of the keys to calculating the capacity of the ARTMVs is determining whether the nonmotorized vehicles overflow into the conflict zone. This paper takes a two-phase signalized intersection as an example to analyze the influence of an overflow of the nonmotorized vehicle queue. 


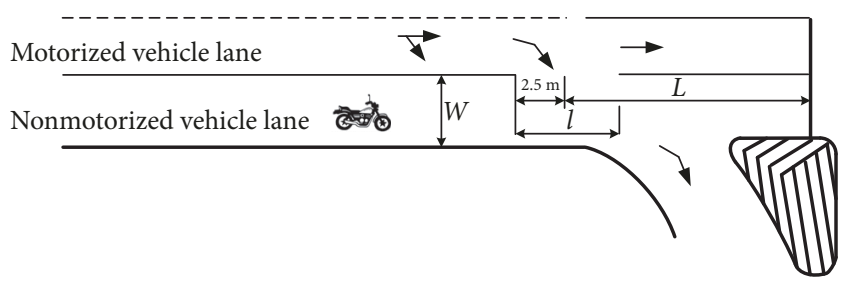

FIGURE 4: Diagram of the crossing process of the ARTMVs.

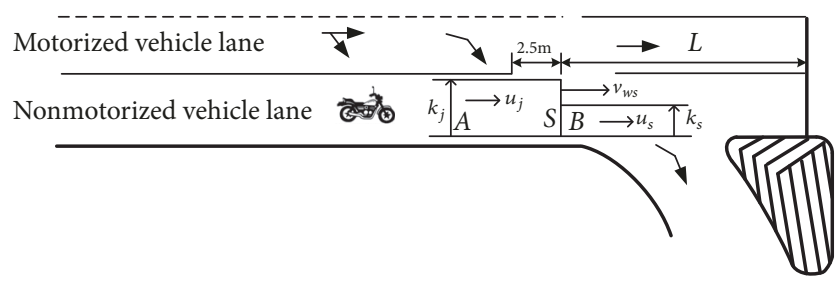

FIGURE 5: Time-space diagram of the shockwave (the starting wave).

According to the observations that were made by the authors, when the opening into the crossing of the ARTMVs was less than $2.5 \mathrm{~m}$ after nonmotorized vehicles queue overflowed, the ARTMVs were not able to complete their trip through the conflict zone. This moment was considered the initial moment when the ARTMVs needed to wait to cross the conflict zone, denoted as $\widehat{t}_{L}$, and letting $t_{L}$ be the time from the start of the effective red time to $\widehat{t}_{L}$, which is calculated as follows:

$$
\begin{aligned}
\frac{\lambda t_{L} Q}{3600} & =L W \\
t_{L} & =\frac{3600 L W}{\lambda Q}
\end{aligned}
$$

Here, $\mathrm{L}$ is the distance between the stop line and the position of the vehicle at the moment $\left(\widehat{t}_{L}\right)$ takes place, as shown in Figure 4. $W$ is the width of the nonmotorized vehicle lane, $\lambda$ is the rate of arrival of the nonmotorized vehicles, and $Q$ is the average road area occupied per nonmotorized vehicle when the nonmotorized vehicles are waiting in the queue during the effective red time.

In this paper, the authors used shockwave theory to describe the phenomenon of spillback among nonmotorized vehicle queues. The shockwave theory was proposed by Lighthill-Whitham-Richards (LWR) [10, 11]. The LWR model was used to analyze traffic flow dynamics, and, in particular, for estimating the shockwave boundary and speed [12]. Recently, some researchers have used this model to analyze the characteristics of nonmotorized vehicles $[13,14]$. To analyze the impact of spillback on the nonmotorized vehicle queue, the shockwave propagation and dissipation procedures were as follows. Shockwaves are interfaces between different traffic-flow density conditions in the time-space domain that describe the transitions of different traffic flow density conditions. As shown in Figure 5, according to changes in the density and the volume, the shockwave is the borderline between the density and volume that appear discontinuously in the time-space domain [15]. Areas A and B

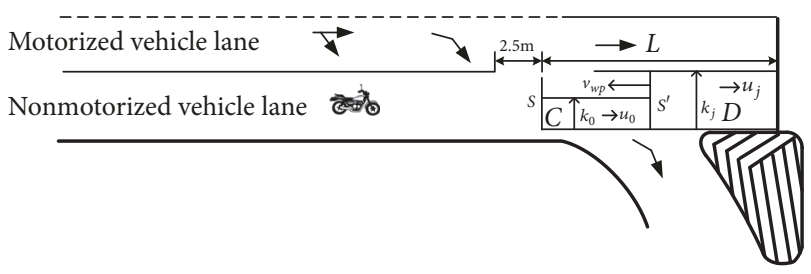

FIGURE 6: Time-space diagram of the shockwave (the stopping wave).

had two different traffic situations with different densities and speeds. They were divided by the perpendicular line $S$ ( $S$ is the location at which the $t_{L}$ happened) and their traffic patterns had a speed of $v_{w s}, u_{j}$ and $k_{j}$ are the volume and the density in Area $\mathrm{A}$, and $u_{s}$ and $k_{s}$ are the volume and the density in Area B. When all of the nonmotorized vehicles pass through the perpendicular line $S$, the ARTMVs can take advantage of the gaps in the flow of nonmotorized vehicles to pass through the conflict zone.

3.2. Time ARTMVs Must Wait before Crossing the Conflict Zone. The authors used the signal cycle as the analytical period to analyze the impact of the spillback on the nonmotorized vehicle queue. In each signal cycle, the time ARTMVs must wait before crossing the conflict zone because of spillback from the nonmotorized vehicle queue is denoted by $T_{l}$, and the determination of $T_{l}$ was divided into the following two situations.

(1) Situation I: when $t_{L} \leq t_{R}$, the nonmotorized vehicles queue had overflowed into the conflict zone during the effective red time and $T_{l}$ could then be calculated as follows:

$$
T_{l}=t_{R}-t_{L}+t_{L}^{\prime}+t_{w s}
$$

Here, $t_{L}{ }^{\prime}$ is the time during which the shockwave propagated backward from the stop line to the perpendicular line $S, t_{L}{ }^{\prime}=$ $L / v_{w p}$, as shown in Figure 6, and $v_{w p}$ can be calculated using Equation (4); $t_{w s}$ is the time required by the nonmotorized vehicle queue before the perpendicular line $S$ dissipated, and $t_{w s}$ can be calculated using the following process.

Step I (the stopping wave speed of the nonmotorized vehicles). As shown in Figure 6, Areas $\mathrm{C}$ and $\mathrm{D}$ had two different traffic situations with different densities and speeds, and they were divided by the perpendicular line $S^{\prime}$ and their traffic patterns had a speed of $v_{w p}$. When the nonmotorized vehicles arrived at the intersection during a red light, the speed $v_{0}$ in Area $\mathrm{C}$ dropped to zero, and the density changed from $k_{0}$ in Area $\mathrm{C}$ to the jam density $k_{j}$ in Area D. The traffic was stopped and the stopping wave formed. According to shockwave theory, the stopping wave speed $v_{w p}$ can be formulated as follows:

$$
v_{w p}=\frac{u_{j}-u_{0}}{k_{j}-k_{0}}=\frac{k_{j} v_{j}-k_{0} v_{0}}{k_{j}-k_{0}}=\frac{-k_{0} v_{0}}{k_{j}-k_{0}}
$$

Here, $u_{0}$ and $u_{j}$ are the traffic volumes of the states before stopping and during the stopped state, respectively. 
Due to the density of the subsequent nonmotorized vehicles during a period of moderate flow, the authors used the Greenshields model to describe this process, which can be formulated as follows $[16,17]$ :

$$
v_{0}=v_{f}\left(1-\frac{k_{0}}{k_{j}}\right)
$$

Substituting Equation (5) into Equation (4) results in the following:

$$
v_{w p}=\frac{-k_{0} v_{f}\left(1-k_{0} / k_{j}\right)}{k_{j}-k_{0}}=-\frac{k_{0}}{k_{j}} v_{f}
$$

Here, $v_{f}$ is the free-flow speed of the nonmotorized vehicles.

Step II (the starting wave speed of the nonmotorized vehicles). After the green light began, the volume changed from zero to the relatively high value of $u_{s}$, the density changed from the jam density $k_{j}$ to a relatively low density $k_{s}$, the nonmotorized vehicles then entered a startup state and began to move, and the starting wave formed. The starting wave speed can be formulated as follows:

$$
v_{w s}=\frac{-u_{s}}{k_{j}-k_{s}}=\frac{-k_{s} v_{s}}{k_{j}-k_{s}}
$$

As a result of the nonmotorized vehicles with states of high density during the initial green time, the authors used the Greenberg model to describe this process [18-20]. This model can be formulated as follows:

$$
u_{s}=k_{s} v_{s}=k_{s} v_{m} \ln \left(\frac{k_{j}}{k_{s}}\right)
$$

Substituting Equation (8) into Equation (7) results in the following:

$$
v_{w s}=-\frac{k_{j} \mathrm{e}^{v_{s} / v_{m}} v_{s}}{k_{j}-k_{j} \mathrm{e}^{v_{s} / v_{m}}}=\frac{\mathrm{e}^{v_{s} / v_{m}} v_{s}}{\mathrm{e}^{v_{s} / v_{m}}-1}
$$

Here, $v_{m}$ is the speed of nonmotorized vehicles with a maximum volume and $v_{s}$ is the speed of the nonmotorized vehicles at the moment they start moving.

Step III (time of the queue dissipation of the nonmotorized vehicles). The dissipation time refers to the time required for the queue of nonmotorized vehicles to dissipate to the perpendicular line $S$, denoted as $t_{w s}$, when the nonmotorized vehicle queue overflows into the conflict zone. According to the flow conservation law, as long as the arrival of the nonmotorized vehicles is confirmed during the ARTMVs' lost waiting time $T_{l}, t_{w s}$ can be calculated using the following formula:

$$
v_{w p}\left(t_{R}-t_{L}+t_{L}^{\prime}+t_{w s}\right) W k_{j}=v_{w s} t_{w s} W k_{s}
$$

By substituting Equation (6) and Equation (9) into Equation (10), the equation can be written as follows:

$$
\begin{aligned}
t_{w s} & =\frac{v_{w p} k_{j}}{v_{w s} k_{s}-v_{w p} k_{j}}\left(t_{R}-t_{L}+t_{L}{ }^{\prime}\right) \\
& =\frac{v_{f} k_{0}}{v_{m} k_{s}-v_{f} k_{0}}\left(t_{R}-t_{L}+t_{L}{ }^{\prime}\right) \\
& =\frac{1}{v_{m} v_{0} k_{s} /\left(\lambda v_{f} / 3600\right)-1}\left(t_{R}-t_{L}+t_{L}{ }^{\prime}\right)
\end{aligned}
$$

(2) Situation II: when $t_{L}>t_{R}$, the nonmotorized vehicle queue may not overflow into the conflict zone during the effective red time. However, with the constant arrival of the nonmotorized vehicles, determining whether the nonmotorized vehicles overflow requires further analysis. This can be calculated using the following process.

Step I (the time of the queue dissipation of the nonmotorized vehicles). Assuming that the queue of nonmotorized vehicles is $L_{t_{R}}$ by the end of the effective red time, $L_{t_{R}}=t_{R} \lambda Q / 3600 \mathrm{~W}$, as shown in Figure 7. The time required for the nonmotorized vehicle queue ahead of the perpendicular line $S$ to completely dissipate is given as $t_{w s}{ }^{\prime}$. According to the flow conservation law, $t_{w s}{ }^{\prime}$ can be calculated using the following formula:

$$
v_{w p}\left(t_{w s}{ }^{\prime}+t_{L}{ }^{\prime}-\frac{\left(L-L_{t_{R}}\right) W}{\lambda Q / 3600}\right) W k_{j}=v_{w s} t_{w s}{ }^{\prime} W k_{s}
$$

By substituting Equation (6) and Equation (9) into Equation (12), the equation can be written as follows:

$$
\begin{aligned}
t_{w s}^{\prime} & =\frac{v_{w p} k_{j}}{v_{w s} k_{s}-v_{w p} k_{j}}\left(t_{L}{ }^{\prime}-\frac{\left(L-L_{t_{R}}\right) W}{\lambda Q / 3600}\right) \\
& =\frac{v_{f} k_{0}}{v_{m} k_{s}-v_{f} k_{0}}\left(t_{R}-t_{L}+t_{L}{ }^{\prime}\right) \\
& =\frac{1}{v_{m} v_{0} k_{s} /\left(\lambda v_{f}\right)-1}\left(t_{R}-t_{L}+t_{L}{ }^{\prime}\right)
\end{aligned}
$$

Step II (the time that the ARTMVs must wait before crossing the intersection). In summary, when $t_{L}>t_{R}$ and $t_{R}-t_{L}+$ $t_{L}{ }^{\prime}+t_{w s}{ }^{\prime}>0$, the nonmotorized vehicle queue has overflowed into the conflict zone, and the ARTMVs lost waiting time $t_{l}$ is equal to $t_{R}-t_{L}+t_{L}{ }^{\prime}+t_{w s}{ }^{\prime}$. When $t_{R}-t_{L}+t_{L}{ }^{\prime}+t_{w s}{ }^{\prime} \leq 0$, the nonmotorized vehicles queue has not overflowed into the conflict zone and $t_{l}$ is equal to zero.

\subsection{Capacity of the ARTMVs When the Nonmotorized Vehicles} Continuously Cross the Conflict Zone. Nonmotorized vehicles did not stop when passing through the conflict zone. These vehicles were usually moving in a state of relatively low density and high speed. Therefore, it could be assumed that the headway of the nonmotorized vehicles followed a negative exponential distribution, and the authors used gap acceptance theory to calculate the capacity of ARTMVs when 


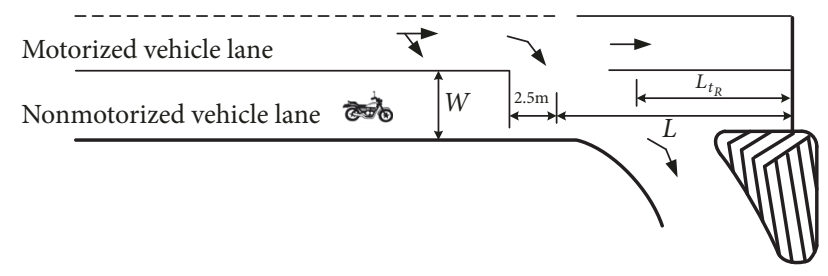

FIGURE 7: The queue of nonmotorized vehicles $L_{t_{R}}$.

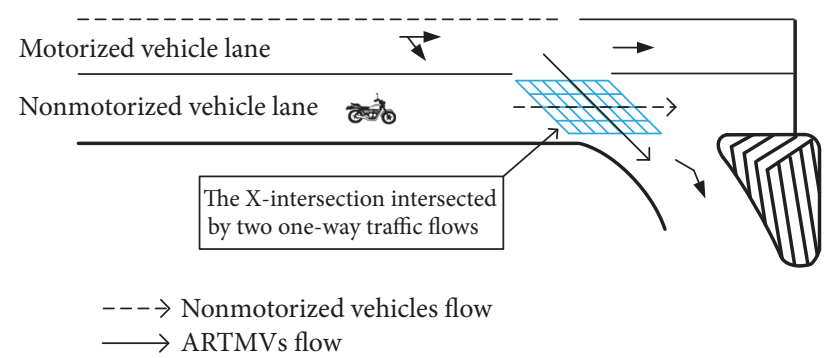

Figure 8: The X-intersection intersected by two one-way traffic flows.

the nonmotorized vehicles continuously crossed the conflict zone [21].

This conflict zone could be considered an X-intersection intersected by two one-way traffic flows, as shown in Figure 8, in which the major traffic flow is composed of nonmotorized vehicles and these vehicles have priority over the ARTMV flow.

The headway of the nonmotorized vehicles is denoted by $t_{n}$, and only when $t_{n}$ is a long period can ARTMVs pass through the nonmotorized vehicle flow. The longer the headway $t_{n}$ is, the larger the number of ARTMVs that will pass through. When the volume of nonmotorized vehicles is zero, the saturation headway of the ARTMVs is denoted by $t_{r s}$, and the minimum headway of the nonmotorized vehicles is $t_{n s}$. Only when $t_{n} \geq t_{r s}+t_{n s}$ do ARTMVs pass through the intersection. Otherwise, these vehicles will make headway against the nonmotorized vehicles for less time than $t_{n s}$. This situation is prone to causing collisions between the ARTMVs and the nonmotorized vehicles. If ARTMVs are to pass through the critical gap $t_{c}$ in the flow of nonmotorized vehicles, $t_{c}$ must be equal to or greater than $t_{r s}+t_{n s}$. Here, the volume of nonmotorized vehicles is $\lambda$. The greater the value of $\lambda$ is, the fewer the ARTMVs that can pass through the conflict zone. The number of ARTMVs that can pass through the conflict zone in a signal cycle $T_{c}$ is given as $C_{T_{c}}$. $C_{T_{c}}$ is a decreasing function that decreases as the number of nonmotorized vehicles increases. There are two common methods of determining $C_{T_{c}}$ : the series method and the integration method. In this paper, the authors used the integration method, which has a relatively simple derivation process. Thus, it was relatively simple to determine the expression of the capacity of the ARTMVs.

The ARTMV lane was thought to meet the needs of the ARTMV queue in this paper. The probability density of $t_{n}$ is $p(t) . T_{t}$ is the time it takes for a nonmotorized vehicle to pass through the conflict zone during a signal cycle assuming that the vehicle does not stop. When the nonmotorized vehicle queue does not overflow into the conflict zone, $T_{t}$ is equal to $T_{c}$ minus $T_{l}$.

For any $t$ and any small increment $\Delta t$ that is greater than $t_{c}$, the probability of $t_{n}$ in the range of $t \sim t+\Delta t$ is $\Delta t p(t)$ and the number of times that $t_{n}$ occurs within this range in a signal cycle is $T_{t} \lambda \Delta t p(t) / 3600$. Then the sum of $t_{c}$ and $t_{r s}$ is divided by $t_{n}$ according to the theoretical deduction. This shows that, during $t_{n}$, the volume of ARTMVs that can pass through the conflict zone is $1+\left(t_{n}-t_{c}\right) / t_{r s}$. Hence, during a signal cycle, the volume of ARTMVs that can pass through the conflict zone is as follows:

$$
\frac{T_{t} \lambda \Delta t p(t)\left(1+\left(t-t_{c}\right) / t_{r s}\right)}{3600}
$$

Let $\Delta t \longrightarrow 0$, and, taking the integral of Equation (14) from $t=t_{c}$ to $t=\infty$, the equation can be written as follows:

$$
C_{T_{c}}=\int_{t_{c}}^{\infty} \frac{T_{t} \lambda \Delta t p(t)\left(1+\left(t-t_{c}\right) / t_{r s}\right)}{3600} d t
$$

Because the ARTMV lane meets the ARTMV queue, the reduction factor of the length of the ARTMV lane for the capacity can be considered equal to 1 . By substituting the probability density function of a negative exponential distribution $p(t)=\lambda / 3600 e^{-\lambda t / 3600}$ into Equation (15), the equation can be written as follows:

$$
C_{T_{c}}=\frac{\lambda T_{t}}{3600} e^{-\lambda t_{c} / 3600}\left(1+\frac{1}{\lambda t_{r s} / 3600}\right)
$$

3.4. Summary of the Model. In a signal cycle, the ARTMVs volume passing through the conflict zone is $C_{T_{c}}=$ $\left(\lambda T_{t} / 3600\right) e^{-\lambda t_{c} / 3600}\left(1+1 /\left(\lambda t_{r s} / 3600\right)\right)$, and $T_{t}$ is determined by whether or not the nonmotorized vehicle queue overflows into the conflict zone. The entire model of the capacity of ARTMVs can be written as follows:

$$
\begin{aligned}
& C_{R}= \frac{\lambda T_{t}}{T_{c}} e^{-\lambda t_{c} / 3600}\left(1+\frac{1}{\lambda t_{r s} / 3600}\right), \\
& T_{t}= \begin{cases}T_{c} & t_{L}>t_{R} \text { and } t_{R}-t_{L}+t_{L}{ }^{\prime}+t_{w s}{ }^{\prime} \leq 0 \\
T_{c}-\left(t_{R}-t_{L}+t_{L}{ }^{\prime}+t_{w s}{ }^{\prime}\right) & t_{L}>t_{R} \text { and } t_{R}-t_{L}+t_{L}{ }^{\prime}+t_{w s}{ }^{\prime}>0 \\
T_{c}-\left(t_{R}-t_{L}+t_{L}{ }^{\prime}+t_{w s}\right) & t_{L} \leq t_{R}\end{cases}
\end{aligned}
$$




\section{Sensitivity Analysis}

Reliability is generally defined as the probability that the system of interest has the ability to perform an intended function or goal. It can be formulated as the determination of the (supply) capacity of the system to meet certain (demand) requirements [22]. The sensitivity of the reliability analysis plays an important role in any assessment of the reliability of an engineering project. This type of analysis has been applied to many aspects of transportation, such as signal timing, sight distance, intergreen intervals at signals, and capacity (e.g., Easa [23, 24]; Chen et al. [25]; Easa [26]; and Zheng et al. [27]). For a sensitivity of reliability analysis, a performance function is obtained from the derivatives of variables. This analysis can be used to analyze the relationship between the change in factors that influence engineering and the degree of change in the results of the engineering project, to identify the factors that influence the results, and to optimize these results in order to ensure the stability and reliability of the engineering application [24]. One of the commonly used sensitivities of reliability analysis models, a first-order probabilistic analysis, is used in this paper.

The model shows that the capacity of ARTMVs is affected by the arrival distribution of nonmotorized vehicles, the arrival rate of nonmotorized vehicles, and signal timing parameters. To fully evaluate the influence of nonmotorized vehicles on ARTMVs, the authors selected the arrival rate of nonmotorized vehicles as the disturbance variable to analyze the sensitivity of the reliability of the model, and it was assumed that other factors were unchanged. During analysis, the arrival rate of the nonmotorized vehicles derived from other influence factors was determined. According to the capacity model of ARTMVs deduced earlier, the sensitivity of the reliability analysis model under the influence of the arrival rate of the nonmotorized vehicles could then be written as follows:

$$
\begin{aligned}
C_{R}^{\prime} & =C_{R}\left|\lambda=\frac{\lambda T_{t}}{T_{c}} e^{-\lambda t_{c} / 3600}\left(1+\frac{1}{\lambda t_{r s} / 3600}\right)\right| \lambda \\
& =\frac{T_{t}}{T_{c}}\left(\left(e^{-\lambda t_{c} / 3600}-\frac{\lambda t_{c}}{3600} e^{-\lambda t_{c} / 3600}\right)\right. \\
& \left.\cdot\left(1+\frac{1}{\lambda t_{r s} / 3600}\right)-\frac{e^{-\lambda t_{c} / 3600}}{\lambda t_{r s} / 3600}\right)
\end{aligned}
$$

The influence of the different arrival rates of nonmotorized vehicles on the capacity of the ARTMVs can be analyzed using Equation (18), which aids in taking effective engineering measures to improve the traffic efficiency of the ARTMVs.

\section{Case Study}

5.1. Traffic Basic Data. To verify the capacity model of the ARTMVs, the Huancheng Bei-Beijing intersection (one of many signalized intersections with channelized islands used for ARTMVs in Kunming, China) was chosen as the model validation site, as shown in Figures 9(a) and 9(b). The authors choose this intersection for two reasons. First, there is a considerable traffic demand at this intersection, which is convenient for traffic conflict analysis. Second, the intersection has a good view, which is convenient for traffic surveying and video recording. A video camera was placed on the pavement in the southwestern corner, and the ARTMVs of the western approach were observed. The ARTMVs were not controlled by the signal. The geometry of the western approach is shown in Figure 9(c). The traffic signal in the intersection had only two phases and it prohibited vehicles from making left turns in all four directions. To fully analyze the conflict between the ARTMVs and the nonmotorized vehicles, the volume of the evening peak was chosen to determine the model calculation parameters. The signal cycle lasted $180 \mathrm{~s}$ during the evening peak, and the yellow interval and the all-red clearance of each phase were $3 \mathrm{~s}$ and $2 \mathrm{~s}$. An illustration of the signal timing is shown in Figure 10, and $T_{G 1}$ and $T_{G 2}$ were the green times during Phase 1 and Phase 2.

5.2. Traffic Parameters of the Model. The video was reviewed using a Corel VideoStudio Pro X4 and the traffic parameters of the model were obtained frame by frame. The video system was set to 25 frames per second. Because about $90 \%$ of the nonmotorized vehicles were electric bicycles, the model parameters were different from those of nonelectric bicycles, as shown in Table 3.

In this example, when $t_{L} \leq t_{R}$ and $\lambda \geq$ $948.127710(\mathrm{veh} / \mathrm{h})$, the nonmotorized vehicle queue had overflowed into the conflict zone, and $T_{t}$ was equal to $T_{c}-\left(t_{R}-t_{L}+t_{L}{ }^{\prime}+t_{w s}\right)$. When $t_{L}>t_{R}$ and $923.122900(\mathrm{veh} / \mathrm{h}) \leq \lambda<948.127710(\mathrm{veh} / \mathrm{h})$, the nonmotorized vehicles queue had also overflowed into the conflict zone, and $T_{t}$ was equal to $T_{c}-\left(t_{R}-t_{L}+t_{L}{ }^{\prime}+t_{w s}{ }^{\prime}\right)$. When $\lambda<923.122900$ (veh/h), the nonmotorized vehicle queue had not overflowed into the conflict zone, and $T_{t}$ was equal to $T_{c}$. By substituting the parameters of Table 3 into Equation (17), the equation could then be written as follows:

$$
T_{t}(s)= \begin{cases}180 & \lambda<923.122900(\mathrm{veh} / \mathrm{h}) \\ 47.505856+\frac{33.974576}{\lambda / 3600}-\frac{132.494144}{3.073479 /(\lambda / 3600)-1}+\frac{33.974576}{3.073479-\lambda / 3600} & \lambda \geq 923.122900(\mathrm{veh} / \mathrm{h})\end{cases}
$$

5.3. Results Analysis. The proposed model was analyzed using data from the survey. First, the capacity of the ARTMVs was calculated using the proposed model. The results of the proposed model were compared to those of the observed 


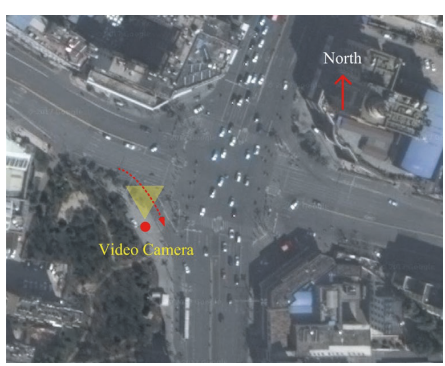

(a)

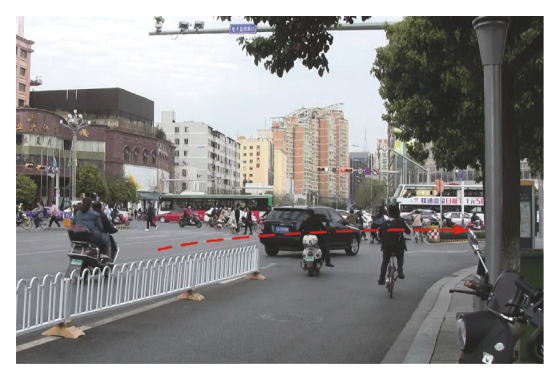

(b)

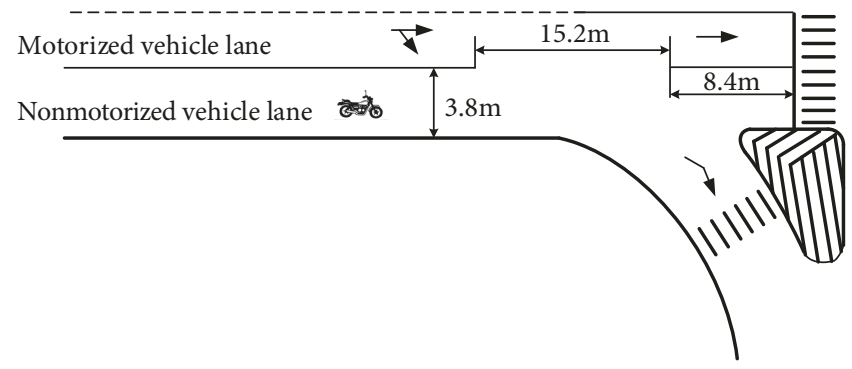

(c)

Figure 9: (a) Video camera location; (b) screen shot; (c) geometry of the Huanchengbei-Beijin intersection.

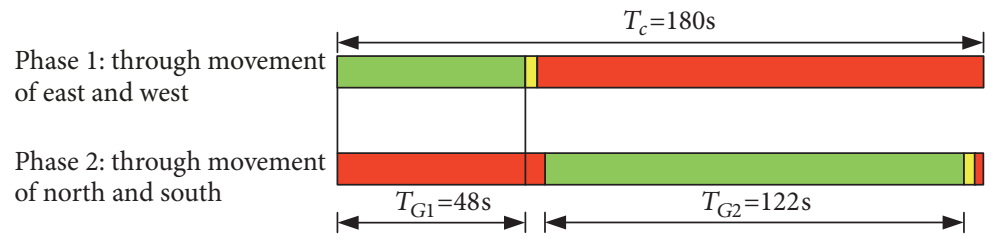

FIGURE 10: Illustration of the signal timing of the Huancheng Bei-Beijing intersection.

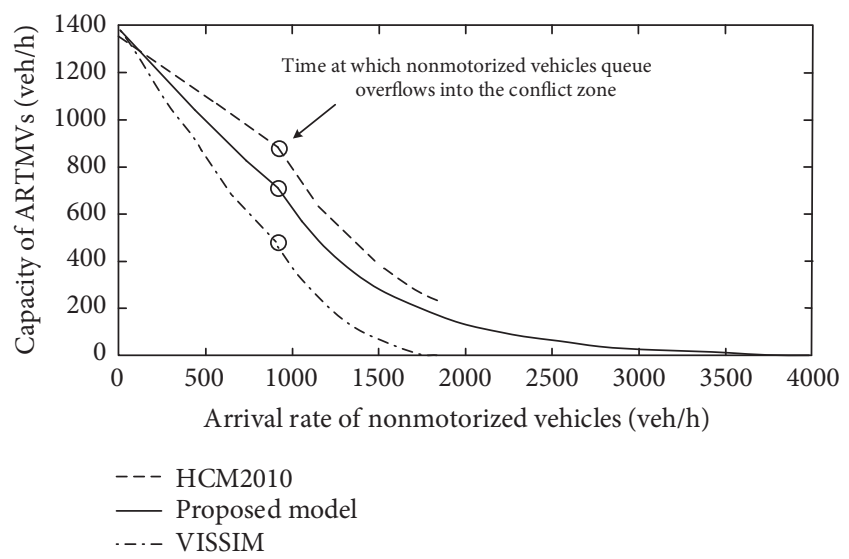

FIGURE 11: The capacity of ARTMVs under different models.

results, the HCM 2010 model (the HCM 2010 model is applicable to the situation in which the flow rate of nonmotorized vehicles is $\lambda \leq 1900$ (veh/h)), and the VISSIM simulation results. Since neither the HCM 2010 model nor the VISSIM simulation model was not used to describe the influence of the queue overflowing on the ARTMVs, the influence of the queue overflowing on the ARTMVs was considered and eliminated by the method of the proposed model before these two models were used. Next, the influence of the nonmotorized vehicle queue overflowing (or not overflowing) on the capacity of ARTMVs was analyzed and compared. The relationship of the capacity of ARTMVs to the distance between the conflict zone and the stop line and the red light of nonmotorized vehicles moving in the same direction was analyzed later. The results were compared to the capacity of the no advance right-turn motorized vehicles (NARTMVs). In this paper, NARTMVs are right-turn motorized vehicles that turn right conventionally without channelized islands. Finally, the authors analyzed the sensitivity of the reliability of the capacity of ARTMVs under the influence of the arrival rate of nonmotorized vehicles. A detailed analysis follows:

(1) Comparison of the capacity of ARTMVs under different models: Figure 11 shows that the results of the proposed model are intermediate between those of the HCM 2010 model and the VISSIM simulation. The overall trends in the results of the three models show that the capacity of the ARTMVs decreased as the arrival rate of nonmotorized vehicles increased. Additionally, the downward trend became more pronounced when the nonmotorized vehicle queue overflowed into a conflict zone. The authors compared these calculated capacities $\left(C_{\text {cal }}\right)$ of the ARTMVs with the observed capacity of the ARTMVs $\left(C_{\text {obs }}\right)$ in Table 4 . The observed 
TABle 3: Parameters of the Model.

\begin{tabular}{|c|c|c|c|c|c|}
\hline Parameters & Values & Sample size & Parameters & Values & Sample size \\
\hline$t_{r s}(\mathrm{~s})$ & 2.6 & 217 & $v_{j}(\mathrm{~m} / \mathrm{s})$ & 0 & - \\
\hline$t_{n s}(\mathrm{~s})$ & 2 & 246 & $v_{s}(\mathrm{~m} / \mathrm{s})$ & 2.8 & 243 \\
\hline$t_{c}(\mathrm{~s})$ & 4.6 & - & $v_{m}(\mathrm{~m} / \mathrm{s})$ & 7.35 & 262 \\
\hline$t_{R}(\mathrm{~s})$ & 129 & - & $v_{f}(\mathrm{~m} / \mathrm{s})$ & 10 & 271 \\
\hline$t_{G}(\mathrm{~s})$ & 48 & - & $k_{j}\left(\operatorname{veh} / \mathrm{m}^{2}\right)$ & 0.32 & 216 \\
\hline$Q\left(\mathrm{~m}^{2} / \mathrm{veh}\right)$ & 2.36 & 169 & $k_{s}\left(\operatorname{veh} / \mathrm{m}^{2}\right)$ & 0.45 & 243 \\
\hline$L(\mathrm{~m})$ & 21.1 & - & $k_{0}\left(\operatorname{veh} / \mathrm{m}^{2}\right)$ & 0.03 & 234 \\
\hline$W(\mathrm{~m})$ & 3.8 & - & & & \\
\hline
\end{tabular}

TABLE 4: Comparison between the Observed and Calculated Capacities of the ARTMVs.

\begin{tabular}{|c|c|c|c|c|c|c|c|}
\hline \multirow{2}{*}{$\lambda(\operatorname{veh} / \mathrm{h})$} & \multirow{2}{*}{$C_{\text {obs }}(\mathrm{veh} / \mathrm{h})$} & \multicolumn{3}{|c|}{$C_{\text {cal }}(\mathrm{veh} / \mathrm{h})$} & \multicolumn{3}{|c|}{ Relative error } \\
\hline & & Proposed model & VISSIM & HCM 2010 & Proposed model & VISSIM & HCM 2010 \\
\hline 113.3 & 1366.7 & 1296.0 & 1264.6 & 1298.8 & $5.2 \%$ & $7.5 \%$ & $5.0 \%$ \\
\hline 260.0 & 1273.3 & 1179.7 & 1109.9 & 1223.6 & $7.4 \%$ & $12.8 \%$ & $3.9 \%$ \\
\hline 353.3 & 1146.7 & 1106.5 & 1012.6 & 1175.7 & $3.5 \%$ & $11.7 \%$ & $2.5 \%$ \\
\hline 473.3 & 973.3 & 1014.8 & 890.4 & 1114.2 & $4.3 \%$ & $8.5 \%$ & $14.5 \%$ \\
\hline 633.3 & 920.0 & 898.4 & 736.0 & 1032.1 & $2.4 \%$ & $20.0 \%$ & $12.2 \%$ \\
\hline 946.7 & 806.7 & 681.5 & 479.9 & 871.5 & $15.5 \%$ & $40.5 \%$ & $8.0 \%$ \\
\hline 1053.3 & 500.0 & 570.8 & 411.8 & 816.8 & $14.2 \%$ & $17.6 \%$ & $63.4 \%$ \\
\hline 1226.7 & 453.3 & 433.1 & 327.6 & 727.9 & $4.5 \%$ & $27.7 \%$ & $60.6 \%$ \\
\hline 1360.0 & 406.7 & 352.6 & 288.5 & 659.5 & $13.3 \%$ & $29.1 \%$ & $62.2 \%$ \\
\hline 1446.7 & 360.0 & 309.2 & 276.6 & 615.0 & $14.1 \%$ & $23.2 \%$ & $70.8 \%$ \\
\hline 1513.3 & 360.0 & 279.7 & 275.2 & 580.9 & $22.3 \%$ & $23.5 \%$ & $61.3 \%$ \\
\hline 1640.0 & 260.0 & 231.5 & 292.7 & 515.9 & $11.0 \%$ & $12.6 \%$ & $98.4 \%$ \\
\hline \multirow[t]{2}{*}{1693.3} & 240.0 & 213.9 & 308.4 & 488.5 & $10.9 \%$ & $28.5 \%$ & $103.6 \%$ \\
\hline & & MAPE & & & $9.9 \%$ & $20.3 \%$ & $43.6 \%$ \\
\hline
\end{tabular}

capacity of the ARTMVs was obtained by observing gaps. This capacity included two parts: the number of vehicles that actually passed and the number of vehicles that could have passed through but did not. The results show that the MAPE (mean absolute percentage error) of the proposed model is the smallest of these three models. This means that the proposed model can describe the traffic characteristics of ARTMVs as a whole better than other two models.

(2) The influence of the overflow of the nonmotorized vehicle queue on the capacity of the ARTMVs: to analyze the difference between the capacity of the ARTMVs with and without a nonmotorized vehicle queue overflow, the authors drew the solid line in Figure 12(a), assuming that the nonmotorized vehicle queue did not overflow into the conflict zone. As shown in Figure 12(a), there was a change point of the ARTMVs capacity when the queue of nonmotorized vehicles overflowed into the conflict zone, and the downward trend of the ARTMVs capacity became more pronounced. As shown in Figure 12(b), when the queue of nonmotorized vehicles overflowed the conflict zone, as the rate of arrival of the nonmotorized vehicles increased to $1500(\mathrm{veh} / \mathrm{h})$, the difference between the capacity of the ARTMVs with and without the nonmotorized vehicle queue overflow rapidly increased to the maximum. This difference was greatest when the nonmotorized vehicles arrival rate was $1500(\mathrm{veh} / \mathrm{h}) \sim 2000(\mathrm{veh} / \mathrm{h})$. As the arrival rate of the nonmotorized vehicles increased, the difference slowly became less pronounced, until it approached zero. When the arrival rate of nonmotorized vehicles was 1000 (veh/h) 2000 (veh/h), the results show that the overflow of the nonmotorized vehicle queue has a profound impact on the capacity of ARTMVs. However, as the arrival rate increased further, the influence of the queue overflow on its capacity decreased gradually until it became negligible.

(3) The relationship of the capacity of ARTMVs with the distance between the conflict zone and the stop line and the effective red time of the nonmotorized vehicles moving in the same direction: the authors analyzed the influence of the overflow of the nonmotorized vehicle queue on the ARTMVs from the perspective of the arrival rate of the nonmotorized vehicles. In addition to the arrival rate of the nonmotorized vehicles, the overflow of the nonmotorized vehicle queue was also affected by other factors.

In this paper, two important factors were selected for further analysis; these two factors were the distance between the conflict zone and the stop line and the effective red time of the nonmotorized vehicles. The authors also compared the results of the capacity of the NARTMVs and provided a theoretical basis for the reasonable traffic control of rightturn motorized vehicles. 


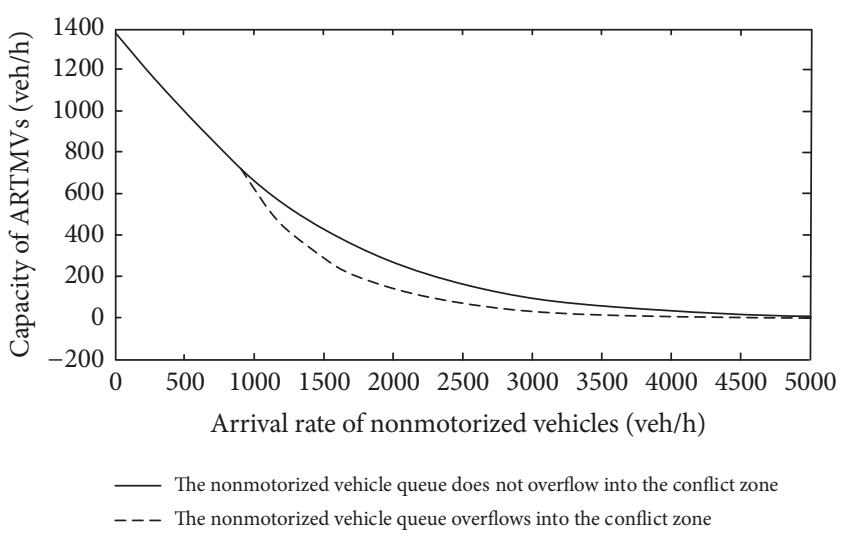

(a)

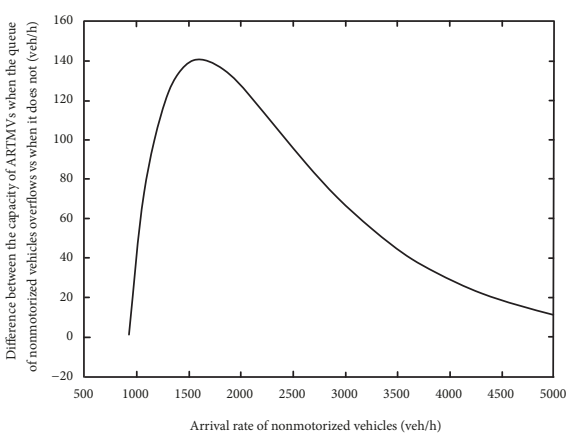

(b)

FIGURE 12: (a) Capacity of the ARTMVs when the nonmotorized vehicles queue did and did not overflow; (b) difference between the capacity of the ARTMVs when the queue of nonmotorized vehicles overflowed and when it did not.

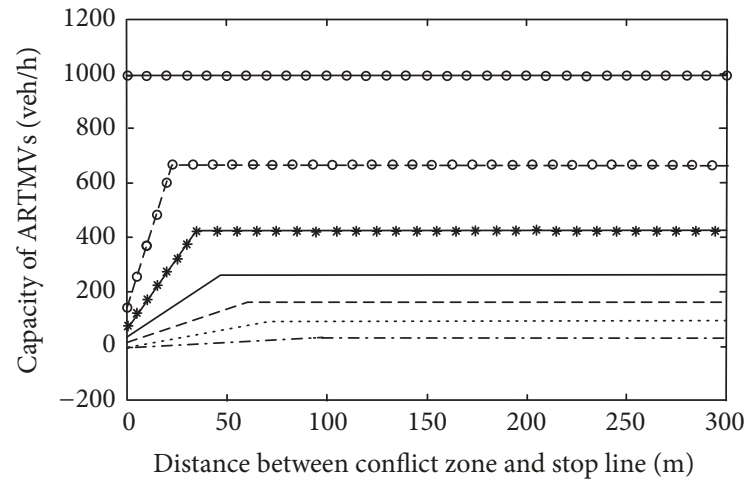

$$
\begin{aligned}
& \lambda \text { :nonmotorized vehicles per hour: } \\
& -\ominus-1000(\mathrm{veh} / \mathrm{h}) \\
& \rightarrow-1500(\mathrm{veh} / \mathrm{h}) \\
& -\quad 2000(\mathrm{veh} / \mathrm{h}) \\
& ---2500(\mathrm{veh} / \mathrm{h}) \\
& \cdots \cdots 3000(\mathrm{veh} / \mathrm{h}) \\
& ---4000(\mathrm{veh} / \mathrm{h}) \\
& -\odot C_{R N}\left(T_{G R}=129 \mathrm{~s}\right)
\end{aligned}
$$

FIGURE 13: Influence of the changes in the distance between the conflict zone and the stop line on the capacity of the right-turn vehicles.

It was assumed that, when comparing the capacity of the ARTMVs and the capacity of the NARTMVs, the effects of pedestrians and other vehicle flows (except for nonmotorized vehicles moving in the same direction) on right-turn vehicles could be ignored, and the NARTMVs and the nonmotorized vehicles were both controlled by the signal. In this situation, the capacity of the NARTMVs was as follows:

$$
C_{R N}=\frac{T_{G R}}{T_{c}} \times S_{r s}
$$

Here, $T_{G R}$ is the effective green time of the NARTMVs, $T_{G R}$ can be considered equal to $t_{R}$, and $S_{r s}$ is the saturation flow rate of NARTMVs, $S_{r s}=3600 / t_{r s}$.
The influence of the change in the distance between the conflict zone and the stop line on the capacity of the rightturn vehicles is described as follows. Figure 13 shows the relationship between the distance between the conflict zone and the stop line and the capacity of the right-turn vehicles, when the time that nonmotorized vehicles spend in the red time is fixed.

According to Figure 13, for different nonmotorized vehicle arrival rates, extending the distance between the conflict zone and the stop line can increase the capacity of the ARTMVs to some extent, and the lower the arrival rate of nonmotorized vehicles is, the more pronounced the effect is. According to the observations that were made by the authors, almost all of the flow rates of the nonmotorized vehicles were less than $4000(\mathrm{veh} / \mathrm{h})$. As shown in Figure 13, when the flow rate of the nonmotorized vehicles was 4000 (veh/h), the distance between the conflict zone and the stop line was close to $100 \mathrm{~m}$. Thus, we can consider that the capacity of ARTMVs is almost unaffected when the distance between the conflict zone and the stop line exceeds $100 \mathrm{~m}$. In addition, this example showed that the nonmotorized vehicles that were moving in the same direction spent $129 \mathrm{~s}$ in a red time, which meant that the NARTMVs had $129 \mathrm{~s}$ of green time to pass through the intersection. During this time, the capacity of the NARTMVs is much greater than that of the ARTMVs, and traffic engineers may consider closing the opening to the conflict zone and using the no advance right-turn method to control the right-turn vehicles.

The influence of the change of the effective red time on the capacity of the right-turn vehicles is described as follows. Figure 14 shows the relationship between the effective red time of the nonmotorized vehicles moving in the same direction and the capacity of the right-turn vehicles when the distance between the conflict zone and the stop line was fixed.

According to Figure 14, for different arrival rates of nonmotorized vehicles, as the duration of the effective red time of nonmotorized vehicles decreased, the capacity of the ARTMVs increased to a certain extent, and the lower the arrival rate of nonmotorized vehicles was, the more 


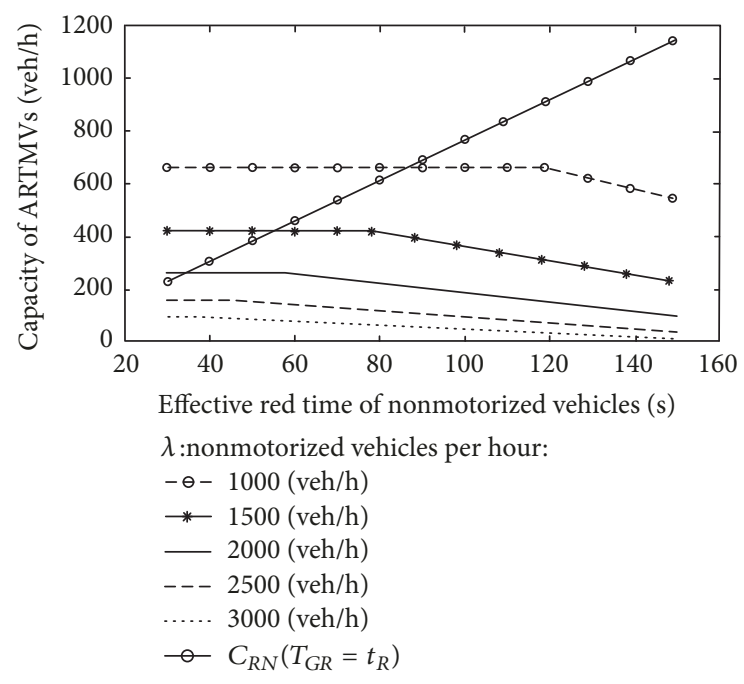

FIGURE 14: Influence of change in the duration of the effective red time on the capacity of the right-turn vehicles.

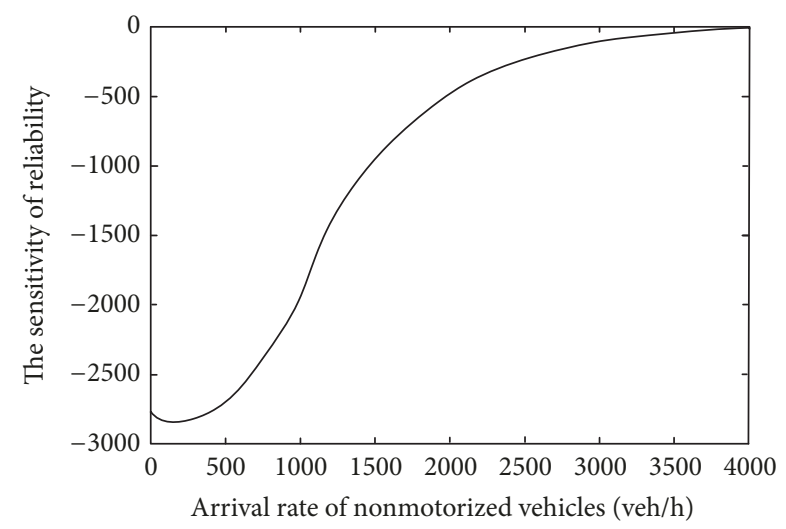

Figure 15: Capacity sensitivities for different arrival rates of the nonmotorized vehicles.

pronounced the effect was. As the duration of the effective red time of nonmotorized vehicles decreased to a certain value, however, the capacity of the ARTMVs was almost unaffected. For the NARTMVs, the longer the effective red time of nonmotorized vehicles was, the greater the capacity was. This example shows that, when the effective red time was longer than $85 \mathrm{~s}$, the capacity of the NARTMVs was greater than the capacity of the ARTMVs. In addition, as the duration of the effective red time of the nonmotorized vehicles increased, the capacity of the NARTMVs also increased and a trend appeared in which the capacity of the ARTMVs was smaller during a lower arrival rate of nonmotorized vehicles and larger during a higher arrival rate of nonmotorized vehicles.

(4) The sensitivity analysis of the capacity of the ARTMVs: Figure 15 shows the relationship between the first order derivative of the capacity of ARTMVs and the arrival rate of the nonmotorized vehicles.

As shown in Figure 15, when the arrival rate of the nonmotorized vehicles was $500(\mathrm{veh} / \mathrm{h}) \sim 2000(\mathrm{veh} / \mathrm{h})$, the capacity of the ARTMVs was more sensitive to changes in the arrival rate of the nonmotorized vehicles. When the arrival rate of the nonmotorized vehicles was 2000 (veh/h) 3000 (veh/h), the sensitivity of the capacity of the ARTMVs to changes in the arrival rate of the nonmotorized vehicles gradually decreased. When the arrival rate of the nonmotorized vehicles was greater than 3000 (veh/h), the sensitivity of the capacity of the ARTMVs to the changes in the arrival rate of nonmotorized vehicles remained basically unchanged.

\section{Conclusions and Discussion}

This paper presents a capacity model of ARTMVs at signalized intersections with mixed traffic conditions using different traffic theories. The proposed capacity model was validated by the data collected at a single intersection with channelized islands in Kunming. This capacity model can be used to analyze the traffic characteristics of right-turn motorized vehicles turning right using channelized islands and nonmotorized vehicles, and to provide theoretical support for traffic management. Based on the results of the analysis, the following conclusions can be reached.

(1) When the arrival rate of nonmotorized vehicles is relatively low, the capacity of ARTMVs can be improved by adopting a method of decreasing the effective red time of the nonmotorized vehicles moving in the same direction or extending the distance between the conflict zone and the stop line. With an increase in the volume of nonmotorized vehicles, however, it is difficult to improve the capacity of ARTMVs by simply decreasing the duration of the effective red time of the nonmotorized vehicles moving in the same direction or by extending the distance between the conflict zone and the stop line. At this point, other methods of optimizing the capacity of ARTMVs must be adopted.

(2) When the arrival rate of nonmotorized vehicles is not very high, the capacity of ARTMVs is more sensitive to changes in the arrival rate of nonmotorized vehicles. When the rate is high, the sensitivity of the capacity of ARTMVs to the change of the arrival rate of nonmotorized vehicles is relatively low. Thus, when the arrival rate of nonmotorized vehicles is not very high, taking appropriate traffic control measures may improve the capacity of the ARTMVs (e.g., extending the distance between the conflict zone and the stop line or increasing the effective green time of the ARTMVs).

(3) When using an advance right-turn method to control the right-turn vehicles, it is necessary to consider the conditions of the intersection, the signal timing scheme, and the arrival rate of nonmotorized vehicles to determine whether the advance right-turn method is desirable. In addition, when the traffic environment varies greatly in different periods of the day, the method of dynamic traffic management, i.e., combining the advance right-turn method and the no advance right-turn method, can be used to improve the capacity of right-turn motorized vehicles by applying the proposed capacity model.

(4) This paper analyzes four aspects of conflicts of ARTMVs, but it does not describe the influence of the interference on these four aspects of conflict involving ARTMVs. For example, when the conflict between pedestrians and ARTMVs is serious, it can cause the influence of the ARTMVs 
to overflow onto the nonmotorized vehicles moving in the same direction. In addition, this paper does not study the capacity of ARTMVs in multiphase signal control. The factors mentioned above will be the focus of further studies to fully and completely reflect the traffic characteristics of ARTMVs at signalized intersections with mixed traffic conditions.

\section{Data Availability}

The survey and analytical data used to support the findings of this study are included within the article.

\section{Conflicts of Interest}

The authors declare that there are no conflicts of interest regarding the publication of this paper.

\section{Acknowledgments}

This work was supported by the National Natural Science Foundation of China [Grant no. 61364019].

\section{References}

[1] R. P. Roess, E. S. Prassas, and W. R. McShane, Traffic Engineering, Pearson Prentice Hall, Upper Saddle River, NJ, USA, 3rd edition, 2004.

[2] G. S. Macfarlane, M. Saito, and G. G. Schultz, "Delay underestimation at free right-turn channelized intersections," Procedia Social and Behavioral Sciences, vol. 16, pp. 560-567, 2011.

[3] S. Farivar, R. Andalibian, and Z. Z. Tian, "Modeling rightturn blockage and approach capacity at signalized intersections with channelized right-turn lanes," Journal of Transportation Engineering, Part A: Systems, vol. 143, no. 2, p. 04016006, 2017.

[4] TRB (Transportation Research Board), Highway Capacity Manual (HCM), TRB (Transportation Research Board), Washington, DC, USA, 2010.

[5] C. Zhou, J. Rong, and C. Shao, "Effects of bicycle traffic on vehicular delays at signalized intersections with pre-right-turn lanes," in Proceedings of the 11th International Conference of Chinese Transportation Professionals (ICCTP), vol. 41, pp. 941952, Nanjing, China, 2011.

[6] Y. Lai, P. Shangguan, J. Rong, and X. Liu, "Influence of pedestrian on capacity of signalized intersection with channelization island," in Proceedings of the 11th International Conference of Chinese Transportation Professionals (ICCTP), pp. 848-858, Nanjing, China, 2011.

[7] Y. Bai and M. Zhang, "Study of pedestrian crossing behavior on the effect of a right-turning vehicle in different intersection channelization mode," in Proceedings of the 14th COTA International Conference of Transportation Professionals, pp. 2107-2117, Changsha, China, 2014.

[8] L. S. Brown and H. Gene Hawkins, "Addressing the need for consistent traffic control devices at channelized right turn lanes," Journal of Transportation Engineering, vol. 140, no. 10, article no. 02514001, 2014.

[9] T. Pan and L. Cheng, "Study of signal control based on conflicts between right-turn vehicles and straight-going bicycles," in Proceedings of the 11th International Conference of Chinese Transportation Professionals (ICCTP), pp. 1111-1116, Nanjing, China, 2011.
[10] M. J. Lighthill and J. B. Whitham, "On kinematic waves: i. flow movement in long rivers. ii. a theory of traffic flow on long crowded roads," Pharmacology \& Therapeutics, vol. 53, no. 3, pp. 275-354, 1955.

[11] P. I. Richards, "Shock waves on the highway," Operations Research, vol. 4, no. 1, pp. 42-51, 1956.

[12] P. Izadpanah, Freeway Travel Time Prediction Using Data from Mobile Probes [PhD diss.], University of Waterloo, 2010.

[13] X. Chen and X. Fang, "The micro individual characteristics in non-motorized traffic mixed of bicycles and mopeds," Journal of Networks, vol. 9, no. 10, 2014.

[14] X. Feng, X. F. Wang, and D. F. Xie, "Lateral drift behavior analysis in mixed bicycle traffic: a cellular automaton model approach," Mathematical Problems in Engineering, vol. 2016, Article ID 7962171, 10 pages, 2016.

[15] H. Cho and Y. Kim, "Analysis of traffic flow with Variable Speed Limit on highways," KSCE Journal of Civil Engineering, vol. 16, no. 6, pp. 1048-1056, 2012.

[16] B. D. Greenshields, "A study of traffic capacity," in Proceedings of the 14 Annual Meeting of the Highway Research Board, pp. 448477, 1935.

[17] H. Wang and T. Wu, "A new united microcosmic model of urban mixed traffic flow," in Proceedings of the 2003 IEEE International Conference on Intelligent Transportation Systems, pp. 156-162, Shanghai, China, 2003.

[18] H. Greenberg, "An analysis of traffic flow," Operations Research, vol. 7, pp. 79-85, 1959.

[19] L. C. Edie, "Car-following and steady-state theory for noncongested traffic," Operations Research, vol. 9, no. 1, pp. 66-76, 1961.

[20] B. G. Heydecker and J. D. Addison, "Analysis and modelling of traffic flow under variable speed limits," Transportation Research Part C: Emerging Technologies, vol. 19, no. 2, pp. 206-217, 2011.

[21] L. Elefteriadou, An Introduction to Traffic Flow Theory, Springer, New York, NY, USA, 2014.

[22] H. S. Ang and W. H. Tang, Probability Concepts in Engineering Planning And Design, Vol. Ii. Decision, Risk, And Reliability, John wiley \& Sons, Inc., New York, NY, USA, 1984.

[23] S. M. Easa, "Reliability-based design of intergreen interval at traffic signals," Journal of Transportation Engineering, vol. 119, no. 2, pp. 255-271, 1993.

[24] S. M. Easa, "Reliability approach to intersection sight distance design," Transportation Research Record Journal of the Transportation Research Board, vol. 1701, no. 1, pp. 42-52, 2000.

[25] A. Chen, H. Yang, H. K. Lo, and W. H. Tang, "Capacity reliability of a road network: an assessment methodology and numerical results," Transportation Research Part B: Methodological, vol. 36, no. 3, pp. 225-252, 2002.

[26] A. Hussain and S. M. Easa, "Reliability analysis of left-turn sight distance at signalized intersections," Journal of Transportation Engineering, vol. 142, no. 3, article no. 04015048, 2015.

[27] F. Zheng, H. J. van Zuylen, X. Liu, and S. Le Vine, "Reliabilitybased traffic signal control for urban arterial roads," IEEE Transactions on Intelligent Transportation Systems, vol. 18, no. 3, pp. 643-655, 2016. 


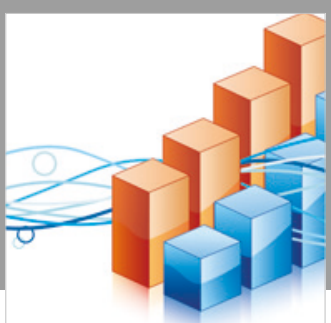

Advances in

Operations Research

\section{-n-m}
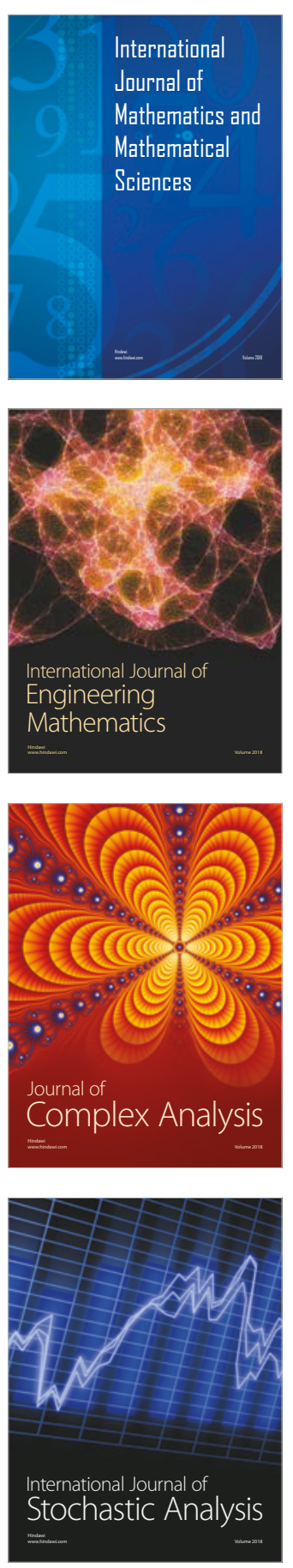
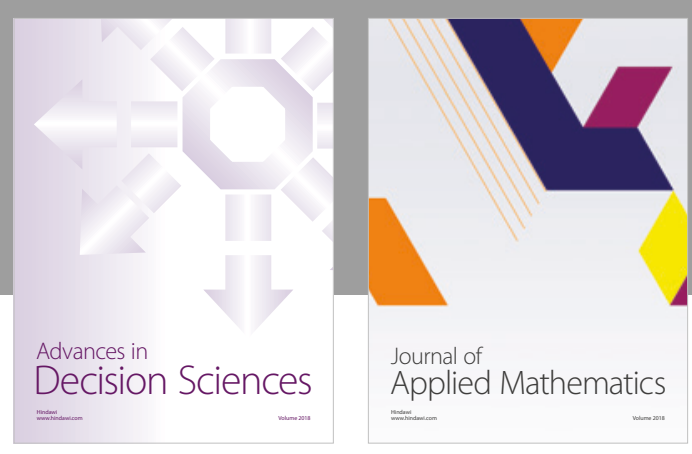

Journal of

Applied Mathematics
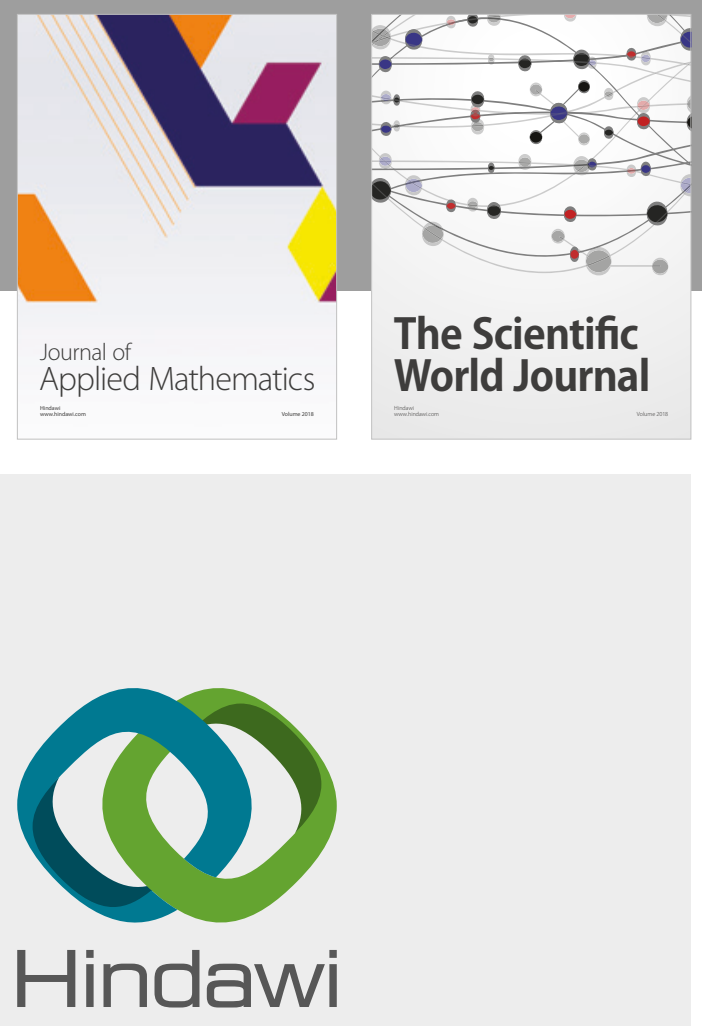

Submit your manuscripts at

www.hindawi.com

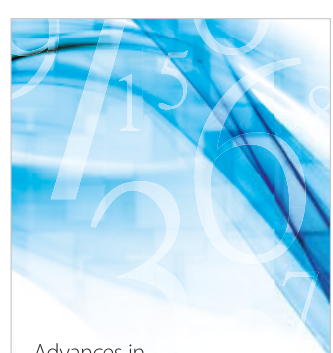

Advances in
Numerical Analysis
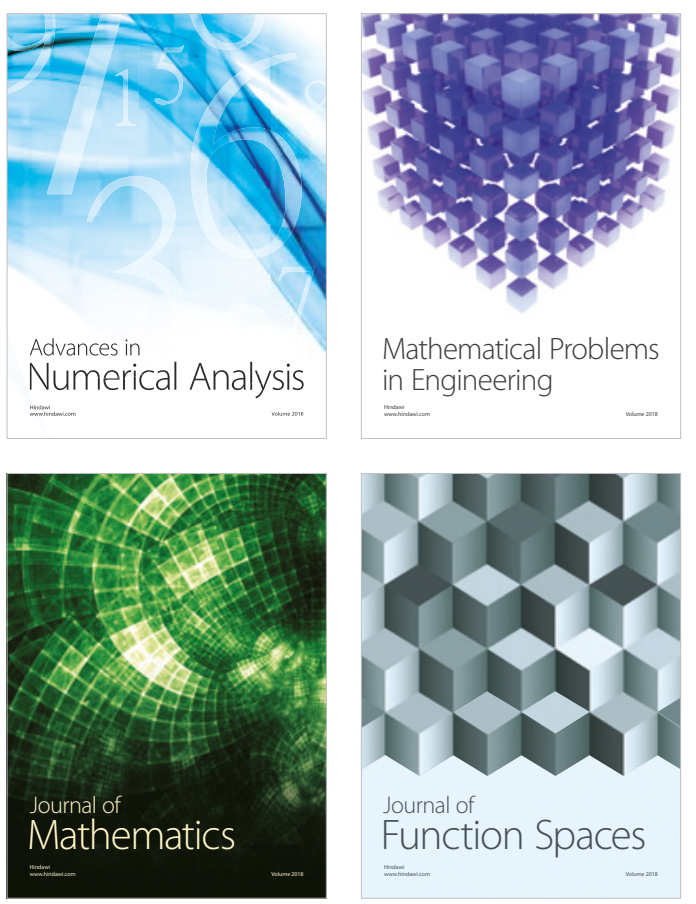

Mathematical Problems in Engineering

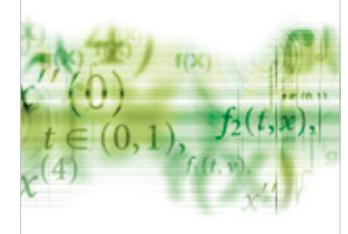

International Journal of

Differential Equations

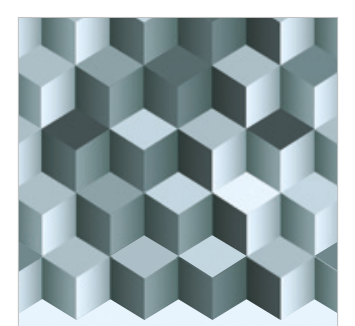

Journal of

Function Spaces

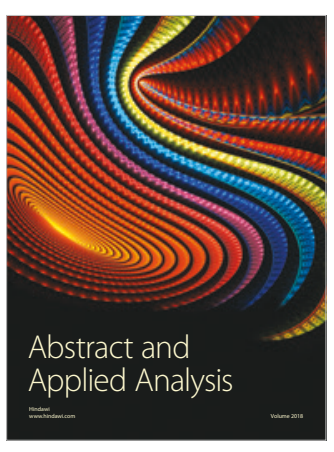

The Scientific

World Journal

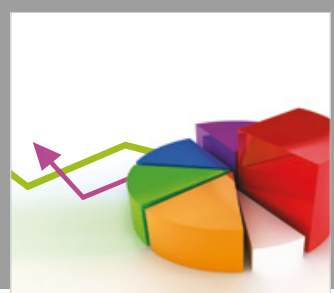

Journal of

Probability and Statistics
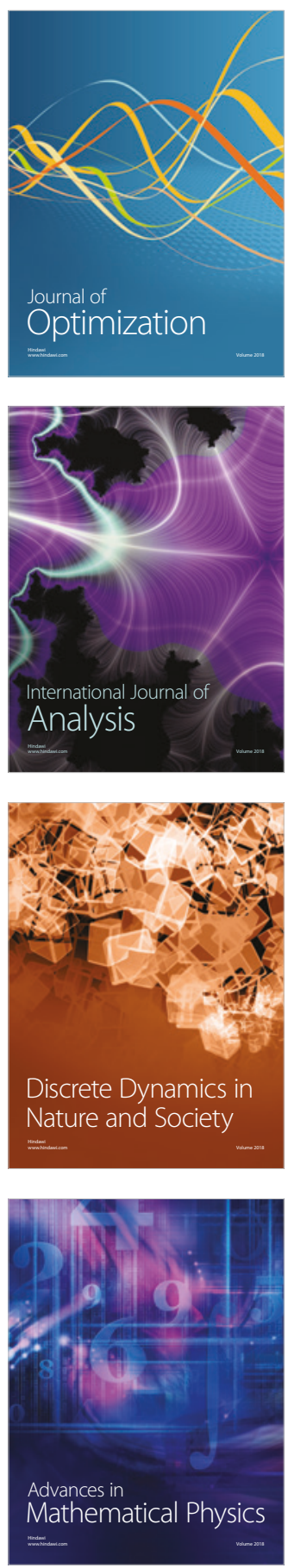